\title{
ACESSIBILIDADE DOMICILIAR DE IDOSOS E A FISIOTERAPIA PREVENTIVA
}

\section{Constância Karyne da Silva Coelho' \\ Lívia Danyelle Viana Lima² Janaina de Moraes Silva ${ }^{3}$}

Resumo: Quedas em idosos são comprometedoras da saúde e acontecem na sua maioria no ambiente domiciliar, pois é o lugar em que passam mais tempo. A prevenção de quedas requer cuidados especiais, o ambiente do domicilio deve ser adaptado. O estudo teve como objetivo analisar as condições de acessibilidade domiciliar de idosos e verificar sua satisfação em relação a sua residência. Foi um estudo observacional, de corte transversal, com abordagem quantitativa. Amostra de 15 idosos na primeira velhice (60 - 69 anos), ativos e independentes. A coleta foi realizada no domicilio, foi aplicado um questionário sobre a casa e o Roteiro de Avaliação do Ambiente. Foi encontrado maior risco de queda em passagens com menos de 90 centímetros, principalmente na cozinha, tapetes foram o obstáculo mais presente principalmente nos banheiros e piso das casas. Alguns idosos conheciam sobre o tema da pesquisa e se mostraram receptivos a adaptações.

Palavras-chave: Idoso; Acessibilidade; Quedas.

\footnotetext{
${ }^{1}$ Fisioterapia/Faculdade Maurício De Nassau, Brasil. E-mail: c.karynecoelho@hotmail.com.

2 Fisioterapia/Faculdade Maurício De Nassau, Brasil. E-mail: liviadanyellevl@hotmail.com.

${ }^{3}$ Fisioterapia/Faculdade Maurício De Nassau; UESPI. E-mail: fisiojanainams@gmail.com.
} 